

\title{
La paradoja del uso racional de la fuerza. Cárceles colombianas en tiempos de COVID-19*
}

\author{
Norberto Hernández Jiménez ** \\ María Catalina Rodríguez -Borrero*** \\ Valeria Echeverry Rodríguez ${ }^{* * * *}$
}

\section{Resumen}

En este artículo se analiza el uso de la fuerza al interior de los establecimientos de reclusión colombianos. Para esto, se contextualiza la situación carcelaria actual y el efecto que ha tenido la llegada del COVID-19, que desembocó en motines y ameritó la declaratoria de emergencia penitenciaria y carcelaria. Teniendo en cuenta los hallazgos, argumentamos que la racionalidad del castigo y de la fuerza que se emplea en contra de las personas privadas de la libertad, es potente en el texto jurídico pero criticable en la práctica. Las muertes y lesiones de personas privadas de la libertad en la Cárcel La Modelo de la ciudad de Bogotá, en los hechos del 21 de marzo de 2020, deslegitiman las acciones estatales desplegadas en procura de mantener el orden penitenciario y degeneran en una masacre. Palabras clave: motines; uso de la fuerza; emergencia penitenciaria y carcelaria

\section{The paradox of the rational use of force in Colombian jails in times of covid-19}

\begin{abstract}
This article analyzes the use of force in Colombian penitentiaries. It studies the current situation in penitentiaries and the particular effect of the Covid-19 pandemic, which triggered mutinies in some prisons. As a consequence of these mutinies, the government had to declare a state of emergency for the prison system. Our findings let us argue that the rationality of the punishment and the use of force against inmates is appropriate de jure but not de facto. For example, deaths and injuries suffered by inmates at the La Modelo (Jail in Bogotá), during the mutiny on March $21^{\text {st }}, 2020$, affected the legitimacy of the authorities' actions. Instead of maintaining order in the penitentiary, the result was a massacre.
\end{abstract}

Key words: Mutiny; use of force; emergency in the prison system.

\section{0 paradoxo do uso racional da força: centros penitenciários colombianos em tempos de COVID-19}

\section{Resumo}

Nesse artigo se analisa o uso da força no interior dos estabelecimentos carcerários colombianos. Para isto, é contextualizada a situação carcerária atual e o efeito observado com a chegada do COVID-19, que levou a distúrbios e mereceu a declaração de emergência penitenciária e carcerária. Considerando os resultados detectados, argumentamos que a racionalidade do castigo e da força que se empregada contra os detentos, é potente no texto jurídico, mas criticável na prática. As mortes e as lesões dos detentos no Presídio La Modelo da cidade de Bogotá, nos fatos acontecidos em 21 de março de 2020, deslegitimam as ações estaduais realizadas na tentativa de manter a ordem penitenciária e causaram um massacre.

Palavras-chave: motins; uso da força; emergência penitenciária e carcerária.

* Artículo de investigación. Producto derivado del Semillero en Derecho Penitenciario adscrito al grupo de investigación en Justicia Social, Teoría Jurídica General y Teoría Política de la Facultad de Ciencias Jurídicas de la Pontificia Universidad Javeriana. Colombia.

La información y opiniones expresadas en el presente artículo son completamente personales y no reflejan ni representan la opinión de la Organización Internacional para las Migraciones (OIM). En consecuencia, la publicación del mismo no concierne ni está relacionada con las actividades que la coautora desarrolla dentro de dicha organización.

** Profesor de la Pontificia Universidad Javeriana, Colombia. Tutor del Semillero en Derecho Penitenciario. Correo electrónico: norbertohernandezj@javeriana.edu.co. ORCID: 0000-0002-5074-5049

*** Estudiante de la Facultad de Ciencias Jurídicas de la Pontificia Universidad Javeriana, Colombia. Miembro del Semillero en Derecho Penitenciario. Correo electrónico: rodriguezm_a@javeriana.edu.co ORCID:_0000-0002-7563-5102

**** Abogada de la Pontificia Universidad Javeriana, Colombia. Coordinadora del Semillero en Derecho Penitenciario. Correo electrónico: valeria.echeverry@javeriana.edu.co. ORCID: 0000-0002-7422-9188

Cómo citar este artículo: Hernández Jiménez, N.; Rodríguez Borrero, M. C. y Rodríguez Echeverry, V. (2021). La paradoja del uso racional de la fuerza. Cárceles colombianas en tiempos de COVID-19. Estudios de Derecho, 78 (171) 271-296

Doi: 10.17533/udea.esde.v78n171a11

Fecha de recepción: 15/07/2020 Fecha de aceptación: 07/10/2020 


\title{
La paradoja del uso racional de la fuerza. Cárceles colombianas en tiempos de COVID-19
}

\author{
Introducción y horizonte metodológico
}

El 11 de marzo de 2020 la Organización Mundial de la Salud (OMS) declaró la situación causada por la enfermedad COVID-19 como pandemia (El Tiempo, 2020a). La repercusión de esta situación en el contexto nacional se ve reflejada -desde el ámbito normativo- en la declaratoria de la emergencia sanitaria, Resolución 385 del 12 de marzo de 2020, del Ministerio de Salud y el estado de emergencia económica, social y ecológica, Decreto 417 del 17 de marzo de 2020, de la Presidencia de la República, declarado exequible mediante Sentencia C-145 de 2020. Posteriormente, la Presidencia de la República expidió el Decreto 637 del 6 de mayo de 2020 que volvió a declarar el estado de excepción hasta el 6 de junio de 2020 (declarado exequible mediante Sentencia C-307 de 2020).

Una de las consecuencias de esta situación fue obligar al Estado y a la comunidad en general, a dirigir la mirada hacia el mundo ignorado de la privación de la libertad ${ }^{1}$, reactivándose así la alarma por las condiciones dentro de los centros de reclusión y la insuficiencia de los mismos para manejar una emergencia de salud pública que puede, potencialmente, poner en riesgo la vida de los reclusos, debido a que los centros de reclusión del país no cuentan con los servicios médicos suficientes para enfrentarla ${ }^{2}$.

1 "Los prisioneros son personas en quienes la mayoría de nosotros preferiría no pensar. Desterrados de la vista cotidiana, existen en un mundo de sombras que solo entra débilmente en nuestra conciencia. Son miembros de una "institución total" que controla su existencia diaria de una manera que pocos de nosotros podemos imaginar" (N. del T.) (Elsner, 2004, p. 16).

2 Un informe elaborado por la Defensoría del Pueblo en el año 2005 establecía que: "Los informes de las visitas practicadas a diferentes establecimientos penitenciarios y carcelarios por la Oficina en Colombia del Alto Comisionado de las Naciones Unidas para los Derechos Humanos, la Procuraduría General de la Nación y la Defensoría del Pueblo señalan, de manera coincidente, que en esos centros se puede observar, entre otras falencias, insuficiencia de personal médico y de enfermería, carencia de atención nocturna, fallas en el suministro de medicinas, ausencia de atención médica especializada y carencia de instalaciones adecuadas para la prestación de servicios de salud" (Defensoría del Pueblo, 2005, p. 17). Adicionalmente, en un estudio de la Contraloría General de la República, se determinó que en el año 2017 se interpusieron 11.131 tutelas y más de 10.500 derechos de petición provenientes de la población privada de la libertad mediante los cuales se reclamaba la prestación de algún servicio médico (El Tiempo, 2018). A 
Ahora bien, para el 21 de marzo de 2020 se contabilizaban 196 casos de contagio en el país (El Tiempo, 2020c). Esta situación desató protestas (motines) en 13 establecimientos de reclusión, motivadas por la precariedad de las condiciones dentro de los centros penitenciarios y carcelarios, en especial, el hecho de que las áreas de sanidad de estos no cuentan con el personal ni los elementos necesarios para prevenir y mitigar el riesgo de contagio entre los reclusos ${ }^{3}$. A este respecto y teniendo en cuenta que la enfermedad COVID-19 causa una afección respiratoria grave, vale la pena resaltar que, de conformidad con un informe elaborado por la Defensoría del Pueblo en el 2005, “[; ...] las enfermedades más comunes entre la población recluida son las infecciones respiratorias, que se sufren de manera permanente" (Defensoría del Pueblo, 2005, p. 14) ${ }^{4}$.

Para enfrentar las protestas al interior de estas organizaciones coercitivas, en donde el uso de la fuerza o la amenaza de su uso suelen ser empleados (Griffin, 1999, p. 1), las autoridades desplegaron no solo a los guardias del Instituto Penitenciario y Carcelario (INPEC), sino además, al Escuadrón Móvil Antidisturbios (ESMAD) de la Policía Nacional. Cabe mencionar que este cuerpo antimotines ha sido objeto de debate en el país por los métodos empleados, convirtiéndose en una problemática contemporánea en el ámbito del control y la seguridad colombiana $^{5}$. Los enfrentamientos entre las personas privadas de la libertad y dichos cuerpos dejaron 24 muertos (Centro de Estudios de Droga y Derecho [CEDD] y Centro de Estudios de Derecho, Justicia y Sociedad [Dejusticia], 2020, p. 19) y casi

su vez, en el informe "Indicadores de Derechos Humanos en el Sistema Penitenciario y Carcelario" se concluye que la situación de goce de servicios de salud en la población privada de libertad es alarmante y urgente (Ministerio de Justicia y del Derecho, Corporación Alemana para la Cooperación Internacional -GIZ-, 2017).

3 Frente a esta situación, es importante mencionar que también se registraron motines en varios países de la región. Cfr. Sociedad de Criminología Latinoamericana (SOCLA) y Centro de Estudios Latinoamericanos sobre Inseguridad y Violencia CELIV (2020, pp. 9-10).

4 “Desde la ONG Dejusticia creen que el temor de los presos es justificado. 'Ha habido brotes de tuberculosis y otras enfermedades respiratorias altamente contagiosas. Esto ha hecho que la población carcelaria tenga un miedo muy grande frente a la llegada del coronavirus', apuntó Juan Sebastián Hernández, investigador de la línea de sistemas judiciales de Dejusticia" (DW, 2020).

5 Tras la muerte de Dilan Cruz el 25 de noviembre de 2019, un joven que hacía parte de las protestas enmarcadas en el Paro Nacional, se publicaron una serie de investigaciones sobre el abuso de la fuerza por parte de los miembros del ESMAD, lo que ha ocasionado, hasta el momento, la muerte de por lo menos 34 personas (Cerosetenta, 2019). Mediante sentencia de tutela del 22 de septiembre de 2020 (STC7641-2020, Radicación n.o 11001-22-03-000-2019-02527-02, M.P. Luis Armando Tolosa Villabona), la Sala de Casación Civil de la Corte Suprema de Justicia analiza, entre otros, el caso de Dilan Cruz (fundamento 5.2.8.1.1.4.), advirtiendo que no era necesario ni proporcional "utilizar el arma larga para disuadir o evitar una antijuricidad de carácter relevante, irremediable, inminente e impostergable para salvaguardar un bien jurídicamente tutelado haciendo uso de ese instrumento para herir al ciudadano" y en varios apartados se recrimina el "actuar impulsivo" del ESMAD. En la investigación titulada: "Monitor del Uso de la Fuerza Letal en América Latina: Un estudio comparativo de Brasil, Colombia, El Salvador, México y Venezuela" se hace un análisis sobre el abuso en el control de la movilización y la protesta por parte del ESMAD, advirtiendo la utilización de armamento no letal, que ha causado varias muertes (Monitor Fuerza Letal, 2019, pp. 51-56). 
un centenar de heridos (entre ellos 11 guardias), solo en la cárcel y penitenciaría de media seguridad de Bogotá "La Modelo"6 (CPMS La Modelo).

En virtud de lo anterior, el 22 de marzo del 2020 se declaró la emergencia carcelaria en el país ${ }^{7}$. Es importante anticipar que esta declaratoria no resuelve el problema penitenciario y contiene un reducido alcance frente a aspectos administrativos, dentro de los cuales se encuentra la facultad de hacer uso racional de los medios extraordinarios de coerción y el reclamo del apoyo de la Fuerza Pública para garantizar el orden dentro de las penitenciarías y centros de reclusión del país. Por su parte, el Gobierno Nacional expidió el Decreto legislativo 546 del 14 de abril de 2020, declarado exequible mediante la sentencia C-255 de 2020, que adopta medidas para sustituir la pena de prisión y la medida de aseguramiento de detención preventiva en establecimientos penitenciarios y carcelarios por la prisión domiciliaria y la detención domiciliaria transitorias en el lugar de residencia, a favor personas que se encuentran en situación de mayor vulnerabilidad frente al COVID-19. Las restricciones que consagra esta norma jurídica tampoco permiten una apertura significativa como válvula de escape del sistema penitenciario y carcelario colombiano, al punto que para la fecha solo se han beneficiado 945 personas, cuya representatividad es baja frente a la totalidad de la población privada de la libertad. De esta manera se puede afirmar que las críticas ${ }^{8}$ formuladas en contra de este decreto legislativo fueron acertadas. Eso sí, resulta más alentadora la actividad ejercida por los jueces de ejecución de penas en aplicación de las medidas ordinarias, que han liberado a 14.514 personas y le han sustituido la pena intramural por domiciliaria (artículo 38 del Código Penal) a 11.680 personas.

6 Una infografía sobre la situación presentada el 21 de marzo de 2020 en este establecimiento de reclusión en Cerosetenta (2020b).

7 Dentro de este contexto, la Corte Constitucional mediante Auto fechado 24 de marzo de 2020, solicita a algunos de los actores del sistema penitenciario y carcelario, que le brinden información sobre las medidas implementadas para disminuir el riesgo de contagio de COVID-19, así como de las estrategias para mitigar sus efectos en los establecimientos de reclusión en el país. Con posterioridad, mediante Auto 157 del 6 de mayo 2020, se adoptan medidas relacionadas con la situación de la Cárcel de Villavicencio, una de las más afectadas por la crisis sanitaria, contando con aspectos positivos como la priorización del comportamiento intramuros frente la valoración de la conducta para la concesión de la libertad condicional y la valoración médica para la prisión intrahospitalaria por parte del personal médico penitenciario y carcelario. Con el objetivo de recaudar más información, el 3 de junio de 2020 se emitió otro auto.

8 Cfr. https://revistes.ub.edu/index.php/CriticaPenalPoder/article/view/31392

- Estudios de Derecho, N. ${ }^{\circ 171}$ ene-jun 2021, ISSN 0120-1867 • ISSN-e 2145-6151 •
- Doi: 10.17533/udea.esde.v78n171 275 • 


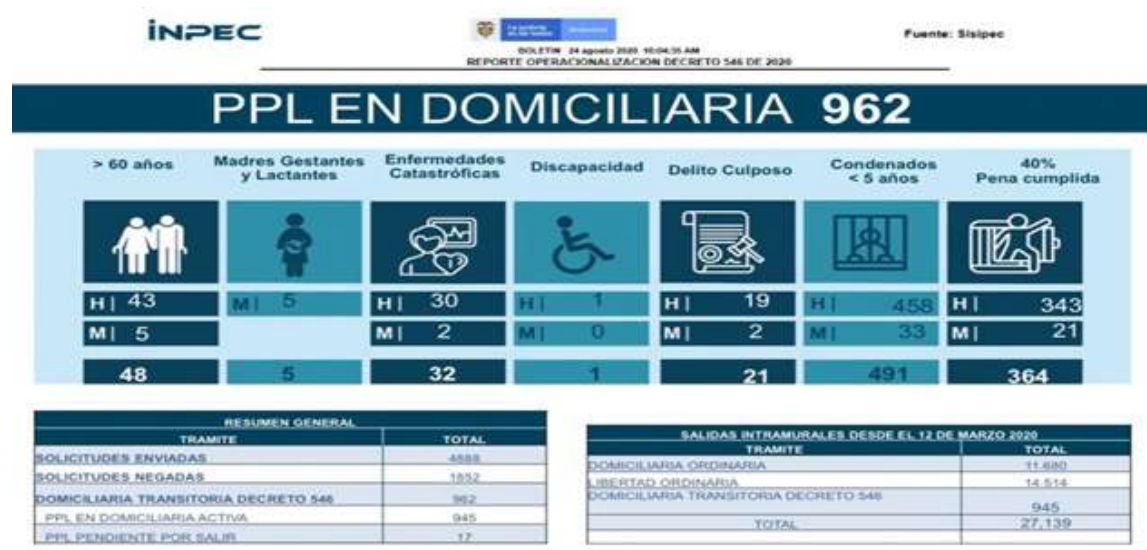

Fuente: Boletín del 24 de agosto de 2020. Reporte operacionalización del Decreto 546 de 2020. SISIPEC.

Así, el presente documento hace una historiografía del tiempo presente (Fazio, 1998), utilizando la prensa como fuente documental (Acevedo y Villabona, 2020; Hernández, 2017) ${ }^{9}$, con el objetivo de documentar los acontecimientos acaecidos el 21 de marzo de $2020^{10} \mathrm{y}$ de esta forma, poder responder a la siguiente pregunta de investigación: ¿Qué tan racional es el uso de la fuerza al interior de los establecimientos de reclusión en tiempos de COVID-19? Igualmente, se estudian las implicaciones de la declaratoria de emergencia carcelaria en el país, enfocados en las facultades con que cuenta el director del INPEC para hacer uso racional de fuerza, para lo cual se recaudaron los principales actos administrativos expedidos con posterioridad al 22 de marzo de 2020. Para describir el contexto carcelario, desde una perspectiva cuantitativa, se recolectaron las estadísticas oficiales en torno al hacinamiento y los contagios del COVID-19 al interior de los establecimientos de reclusión.

La estrategia metodológica se completó con una revisión bibliográfica acerca de la evolución de la pena privativa de la libertad (Hernández, 2018, pp. 39-46) y los parámetros de racionalización del castigo ${ }^{11}$ (Umaña y Cordero, 2019). Todo esto con

9 Al respecto, advierte Larrauri (2015), que las noticias aparecidas en los medios de comunicación, entre otras fuentes, brindan información abundante para las investigaciones criminológicas, en aplicación del método cualitativo de análisis documental (p. 48).

10 Para la fecha de elaboración de este artículo, la situación de cuarentena imposibilitó el trabajo de campo, sumado a las restricciones de ingreso a los establecimientos de reclusión en virtud de la pandemia, para recaudar información in situ. Asimismo, debe advertirse que actualmente se vienen adelantando investigaciones por los organismos de control del Estado, cuya información no se encuentra disponible.

11 “(...) el castigo se ha convertido, por lo menos hasta cierto punto, en una forma racionalizada de práctica social” (Garland, 1999, p. 212). Esto se opone al pensamiento de Durkheim que considera que "el castigo moderno sigue siendo un asunto irracional, emocional y especialmente punitivo" (Garland, 1999, p. 224). 
la finalidad de determinar la coherencia entre los procedimientos y el respeto de los derechos humanos radicados en cabeza de la población privada de la libertad.

\section{Situación carcelaria en tiempos del COVID-19}

Durante décadas se ha hablado en Colombia sobre la crisis ${ }^{12}$ que atraviesa el sistema carcelario (Hernández, 2018, p. 19; Iturralde, 2011, p. 112), la cual se debe, en gran medida, a las inhumanas condiciones dentro de los centros penitenciarios del país, como consecuencia del hacinamiento, que es una característica transversal en la mayoría de los sistemas penitenciarios del mundo (Grujić \& Milić, 2016, p. 286). No obstante, hasta el momento, el Estado ha fallado en tomar medidas que sean realmente efectivas para mejorar dicha situación.

La Corte Constitucional declaró el estado de cosas inconstitucional ${ }^{13}$ en el sistema penitenciario y carcelario (ECI carcelario). Las Sentencias T-153 de 1998, T-388 de 2013 y T-762 de $2015^{14}$ contienen pronunciamientos concretos mediante los cuales se insta a distintas entidades públicas a actuar dentro de su competencia para evitar la vulneración de los derechos fundamentales de los reclusos.

De hecho, en la Sentencia T-388 de 2013 se hace hincapié en que dentro de los centros de reclusión la violación de derechos fundamentales es atroz y que la población privada de la libertad debe considerarse como personas que se encuentran en situación de vulnerabilidad manifiesta ${ }^{15}$, debido a que están recluidas en un lugar que se encuentra en un estado contrario a lo que consagra la Constitución ${ }^{16}$, ya que la sobrepoblación conlleva una mayor dificultad para garantizar condiciones de reclusión dignas, entre las cuales se encuentra la prestación adecuada del servicio de salud ${ }^{17}$. Este ambiente es propicio para la propagación de infecciones

12 El término traspasa el ámbito local, con miras a describir la institución carcelaria en otros contextos. Véase: Matthews (2003, pp. 317 y 334).

13 Esta figura es de origen jurisprudencial y parte del reconocimiento de una situación en la que se presenta una violación masiva de derechos que merece la especial atención de los poderes públicos para proteger derechos fundamentales que se ven amenazados (Quintero, Navarro y Meza, 2011).

14 Las referencias que dentro de este texto se hagan a las providencias precedidas por los literales C-y T- corresponden a sentencias de constitucionalidad y de tutela, respectivamente, proferidas por la Corte Constitucional, organismo perteneciente a la Rama Judicial del Poder Público en Colombia, Corporación a la que el constituyente primario le confió la guarda de la integridad y supremacía de la Constitución Política.

15 “(...) El nivel y grado tan atroz de violación de los derechos fundamentales de las personas privadas de la libertad, así como la cantidad y variedad de violaciones. Se trata de personas en situación de vulnerabilidad manifiesta, dada la relación de especial sujeción que supone estar preso, aparte del estado de cosas contrario a la Constitución en que se encuentra el Sistema carcelario, que amplifica las violaciones y amenazas" (Sentencia T-388 de 2013).

16 Una crítica a la manera como la Corte Constitucional ha abordado esta problemática, en Escobar (2018).

17 Desde la Sentencia T-606/98 se había declarado el estado de cosas inconstitucional respecto a la salud, asistencia médica y suministro de medicamentos para la población reclusa. Dentro de los ejes temáticos definidos por la Corte 
letales, resaltando la literatura, entre otras, la tuberculosis, la neumonía y las enfermedades parasitarias (Limoncelli, Mellow \& Na, 2020, p. 11).

Frente al hacinamiento carcelario, entendido como la diferencia existente entre el número de plazas o cupos y el número de internos (Hernández, 2018, p. 89), se evidencian los siguientes datos en la actualidad, estos corresponden al índice más bajo desde el año 2011 (López, 2020), respecto de los establecimientos penitenciarios y carcelarios administrados por el INPEC:

Gráfico n. ${ }^{0}$ 2. Hacinamiento carcelario

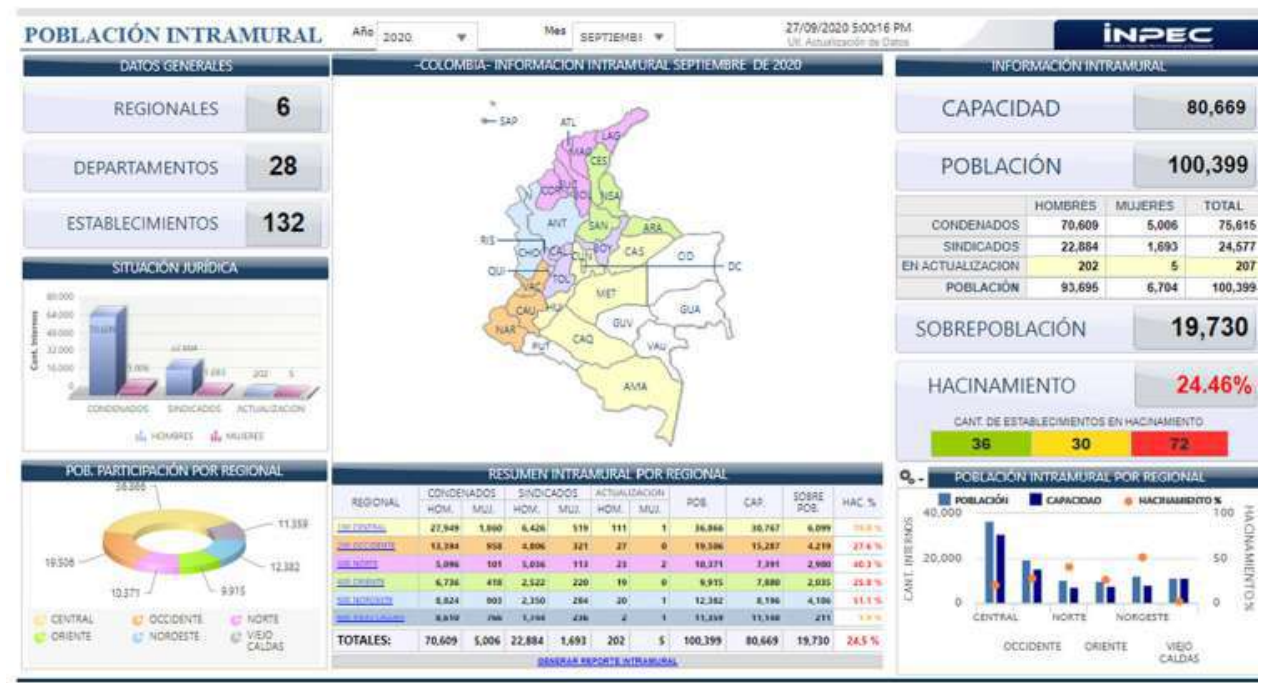

Fuente: Tableros estadísticos INPEC (27-09-20).

La situación carcelaria se ha agravado como consecuencia de la pandemia, ya que el hacinamiento carcelario -dentro de un contexto espacial que puede ser catalogado como un "no - lugar" (Augé, 2005; Gutiérrez, 2018)-, se convierte en un factor de riesgo para la salud de las personas privadas de la libertad, quienes no cuentan con la posibilidad de practicar el distanciamiento social ni las medidas profilácticas para evitar el contagio de COVID-19. Esta situación es pregonable de manera generalizada en el contexto latinoamericano ${ }^{18}$.

Constitucional en el Auto 121 de 2018, que reorientó la estrategia de seguimiento del ECI carcelario, se señala, entre otras, la problemática de salud.

18 “Así, el COVID-19 llegó a las cárceles de Latinoamérica desnudando sus grandes fragilidades y acelerando los conflictos y retos que ya presentaba. Al hacinamiento, la escasez de recursos y bienes se suma el desafío sanitario de atender población vulnerable, la necesidad de establecer nuevos protocolos que restrinjan la esencial comunicación de los presos con sus familias, y el temor a un contagio masivo que presione sobre los ya precarios sistemas hospitalarios 
Empero, la existencia de esta circunstancia aumenta el riesgo al que están expuestas las personas privadas de la libertad frente al Coronavirus, puesto que, al tratarse de un virus altamente contagioso (Centros para el Control y la Prevención de Enfermedades (CDC) 2020), el hacinamiento carcelario presupone una mayor posibilidad de contagio entre los internos, al no permitir la realización de actividades de prevención (Uprimny, 2020). A lo anterior debemos sumarle que los centros de reclusión en Colombia no cuentan con el personal médico suficiente para atender a las personas privadas de la libertad en condiciones normales, mucho menos lo será durante una pandemia. Según información de la ONG Temblores, el INPEC cuenta solamente con 512 enfermeros y auxiliares de enfermería para atender a los reclusos de todo el país y hay por lo menos 5 centros de reclusión que no tienen ni un solo profesional de la salud (Morales, 2020).

Para mostrar esta problemática en cifras, a continuación, se relacionan los establecimientos de reclusión que tenían confirmados casos positivos de COVID-19 para junio de 2020 , así como los fallecimientos de la población privada de la libertad por esta enfermedad.

Tabla 1. Establecimientos de reclusión con casos positivos de COVID-19

\begin{tabular}{|c|c|c|c|c|c|c|c|c|c|c|}
\hline \multirow{3}{*}{ No. } & \multirow{3}{*}{ ERON } & \multirow{2}{*}{\multicolumn{3}{|c|}{$\begin{array}{c}\text { Confirmados } \\
99,71 \%\end{array}$}} & \multirow{2}{*}{\multicolumn{3}{|c|}{$\begin{array}{c}\text { Fallecidos } \\
0,29 \%\end{array}$}} & \multirow{3}{*}{ Total } & \multirow{3}{*}{8} & \multirow{3}{*}{ UBICACIÓN } \\
\hline & & & & & & & & & & \\
\hline & & Hombre & Mujart & Subtotal & Homber & Mujer & Subtotal & & & \\
\hline 1 & Letcia EPMSC & 4 & 0 & 4 & 1 & 0 & 1 & 5 & 2988 & ERON Pabelibn Especis, (01) Defuncion en Domicilara \\
\hline 2 & COBOG Bogot (Picota) & 10 & 0 & 10 & 0 & 0 & 0 & 10 & $0,12 \mathrm{~K}$ & ERON Pabelion Especial \\
\hline 3 & EP Forencia Las Helicenias & 1 & 0 & 1 & 0 & 0 & 0 & 1 & 0,075 & ERON (UTE). \\
\hline 4 & EP Guaduas La Esperanza & 1 & 0 & 1 & 0 & 0 & 0 & 1 & 0,045 & ERON Pabelín Especial \\
\hline 5 & CPMS Espiral & 1 & 0 & 1 & 0 & 0 & 0 & 1 & 0.115 & ERON Pabelbn Especial \\
\hline 6 & EPUSC Villavicencio & 780 & 0 & 780 & 2 & 0 & 2 & 782 & $49.78 \%$ & Pabelćn Espesal induye (02) Detunciones. \\
\hline 7 & EPMSC TImass & $B 1$ & 1 & 82 & 0 & 0 & 0 & 82 & $16,27 \mathrm{~S}$ & ERON Pabellon Especia \\
\hline 8 & EPUSC Call & 270 & 0 & 270 & 1 & 0 & 1 & $2 \pi 1$ & $5,08 \%$ & ERON Pabellon Especia (01) Deluncion, (05) Hospital UCI \\
\hline 9 & CMSBA Barranquila & 1 & 0 & 1 & 0 & 0 & 0 & 1 & 0,115 & ERON Pabelion Especial \\
\hline 10 & EPMSC Cartagena & 499 & 0 & 499 & 1 & 0 & 1 & 500 & $21,37 \times$ & Pabelicn Espedal ERON irchye (01) Defuncion \\
\hline 11 & EPUSC Santa Mata & 1 & 0 & 1 & 0 & 0 & 0 & 1 & 0.085 & Pabelicn Especial ERON Incluye \\
\hline 12 & EPMSC Barranquila & $2 B$ & 0 & 28 & 0 & 0 & 0 & 28 & 1915 & ERON Pabellinn Especial \\
\hline \multirow[t]{4}{*}{13} & EPMSC Qubdo & $\theta$ & 4 & 13 & 0 & 0 & 0 & 13 & $2,13 \%$ & ERON Pabelión Especia, (01) Hosplialcado \\
\hline & Subtotal & 1.696 & 8 & 1.691 & 5 & 0 & 5 & 1.696 & $1,54 \%$ & \\
\hline & Total & & 1.691 & & & 5 & & \multirow{2}{*}{\multicolumn{3}{|c|}{ 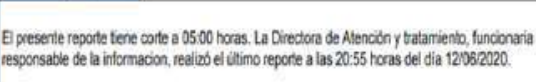 }} \\
\hline & GranTotal & \multicolumn{6}{|c|}{1.696} & & & \\
\hline
\end{tabular}

Fuente: Ministerio de Justicia (2020a, anexo 11, p. 1).

Según lo informado por el Ministerio de Justicia (2020a, p. 75 y anexo 11, p. 1), para el 13 de junio de 2020 se registraban 1.777 casos confirmados activos de

de los países de la región. En resumen, un desafío humanitario y sanitario de grandes proporciones para los sistemas penitenciarios de los países en desarrollo" (SOCLA y CELIV, 2020, p. 4). 
COVID-19 (1.696 personas privadas de la libertad y 81 funcionarios del INPEC) y 5 muertes; a esta última cifra -en concepto de un sector de la academia -, debería sumársele las muertes acaecidas en la CPMS La Modelo como consecuencia de los motines ocurridos el 21 de marzo de 2020 (Hernández, 2020, p. 182).

\section{Estado de emergencia penitenciaria y carcelaria}

El estado de emergencia penitenciaria y carcelaria es una medida que faculta al director del INPEC para realizar ciertos procedimientos, como disponer del traslado $^{19}$ y aislamiento de los internos, hacer uso racional de los medios extraordinarios de coerción y el reclamo del apoyo de la Fuerza Pública, suspender o reemplazar personal penitenciario (siempre y cuando se encuentre comprometida su participación en los hechos que alteran el orden y la seguridad de los establecimientos de reclusión), hacer traslados presupuestales y contratación directa de las obras y servicios necesarios para conjurar la emergencia, previo concepto del Consejo Directivo del Instituto, entre otros.

En este punto y con miras a hacer claridad, es importante diferenciar que una cosa es el estado de excepción (Decretos 417 y 617 de 2020) y otra el estado de emergencia penitenciaria y carcelaria (Resolución 001144 de 2020), habilitando el primero, el uso de ciertas facultades legislativas extraordinarias radicadas en cabeza del Presidente de la República (por ejemplo, la expedición del Decreto 546 de 2020) y el segundo, facultades administrativas por parte del director del INPEC $^{20}$, como se ve reflejado en las medidas relacionadas en la tabla n. $\stackrel{0}{2}$.

De acuerdo con el artículo 168 del Código Penitenciario y Carcelario (CPC), modificado por el artículo 92 de la Ley 1709 del 2014, se podrá decretar el estado de emergencia penitenciaria y carcelaria por cuatro causales ${ }^{21}$. Así las cosas, y tras

19 Mediante oficio 20201E0047778 del 12 de marzo de 2020, el Director de Custodia y Vigilancia del INPEC comunica que la Dirección General suspendió los traslados de la población privada de la libertad.

20 "El estado de emergencia penitenciaria y carcelaria no implica que el Ejecutivo asuma funciones legislativas pues, a través de la precitada figura sólo se están actualizando las restricciones anexas a la suspensión del derecho a la libertad física, precisamente ya determinadas por el propio legislador al regular el régimen penitenciario y carcelario y fijar los propios límites del mencionado estado de emergencia. En ese orden de ideas, el estado de emergencia penitenciaria y carcelaria es una manifestación de potestad administrativa, pues solamente es un procedimiento que permite abreviar y conferir mayor agilidad a ciertos trámites, en relación con las situaciones de normalidad, en virtud de la crisis de seguridad y de orden sanitario a la cual se enfrentan las autoridades carcelarias y penitenciarias. Este estado de emergencia se asimila entonces a otras figuras administrativos, como la llamada contratación estatal por urgencia manifiesta, en las cuáles la ley hace más expeditos ciertos procedimientos y tomas de decisión, por las situaciones de urgencia que enfrenta la administración, sin que por ello pueda decirse que se trata de uno de los estados de excepción regulados por la Carta, puesto que el Ejecutivo sigue estrictamente sometido a la ley y no se convierte en legislador excepcional" (Sentencia C-318 de 1995).

21 (i) Cuando ocurran situaciones que puedan provocar una amenaza al orden y la seguridad penitenciaria; (ii) cuando surjan circunstancias graves de salud, sanitarias, que el estado higiénico del lugar no permita la convivencia o la 
observar los escenarios en los que es posible declarar una emergencia carcelaria, parece evidente que dicha declaratoria debió mantenerse vigente por lo menos desde la declaratoria de ECI carcelario en el año 1998 y sin solución de continuidad, con el objetivo de tomar las medidas necesarias para evitar vulneraciones a los derechos de las personas privadas de la libertad, dado que las circunstancias en las cuales se encuentran recluidas desde hace más de dos décadas conllevan violaciones a sus derechos humanos y fundamentales.

En este sentido, en el año 1998 (Resolución 313) se declaró estado de emergencia penitenciaria y carcelaria (Sampedro, 1998, p. 110) y en el pasado cercano se hizo lo propio mediante las Resoluciones 1505 del 31 de mayo de 2013 (vigente hasta el 31 de diciembre de 2013) y 2390 del 10 de mayo de 2016 (con una vigencia inicial hasta el 31 de diciembre de 2016, misma que fue prorrogada por la Resolución 6401 del 21 de diciembre de 2016, quedando vigente hasta el 30 de junio de 2017). No obstante, y a pesar de la permanente configuración de las condiciones que habilitan esta declaratoria, la figura es inaplicada y en el interregno de su aplicación, ha resultado ineficaz.

Es importante enfatizar que uno de los mayores problemas existentes en la actualidad en materia carcelaria son las deficientes condiciones de higiene, así como la ausencia de la prestación del servicio de salud en condiciones idóneas (artículo 168-2 CPC). Esto, sumado al índice de hacinamiento que alcanza el $24.46 \%$ en los establecimientos penitenciarios y carcelarios administrados por el INPEC ${ }^{22}$ (artículo 168-3 CPC), implica que el virus puede contagiarse a mayor

ocurrencia de una calamidad pública; (iii) cuando el nivel de ocupación interfiera con los derechos fundamentales de la persona privada de la libertad y (iv) cuando se ponga en riesgo el funcionamiento del sistema o se amenacen derechos fundamentales por no prestarse servicios esenciales.

22 Es importante advertir que las estadísticas del INPEC no contabilizan la situación en los centros de reclusión transitorios (Estaciones de Policía y Unidades de Reacción Inmediata), lo que puede influir en la percepción de reducción del hacinamiento (López, 2020), como consecuencia de la omisión en la sumatoria de estos datos. En este sentido, para el 9 de junio de 2020, se registraban 11.980 personas privadas de la libertad en estos centros de reclusión transitorios, lo cual muestra un incremento de 2.761 personas en los últimos 3 meses (Ministerio de Justicia, 2020a, p. 109). Adicionalmente, en respuesta a los autos del 19 de junio y 3 de julio de 2020 proferidos por la Corte Constitucional, en relación con el control automático de constitucionalidad frente al Decreto 804 de 2020, el Ministerio de Justicia (2020b), señala que: “4.1.2. A partir de los datos descritos se tiene el siguiente resultado final: en todo el país, las salas de la Policía Nacional suman un total de 1123, con una capacidad para albergar a 4825 personas, pero con una ocupación que, para la fecha del informe, ascendía a 10844 personas recluidas. De ellas, 1382 tienen calidad de condenados y 9462 tienen calidad de sindicados, donde 10402 pertenecen el género masculino, 430 pertenecen al género femenino y 12 son Lgtb. Esto arroja una cifra de 6019 personas adicionales y un índice de hacinamiento del 124,75\%" (p. 12) (Resaltado fuera del texto), y más adelante "6.1.6. De esa manera, los centros de detención transitoria, especialmente las salas de las estaciones de policía, vienen afrontando condiciones de hacinamiento que dificultan mantener espacios de higiene y saneamiento para las personas privadas de la libertad que se encuentran detenidas en ellos" (Ministerio de Justicia, 2020b, p. 17). Incluso, otras fuentes señalan un hacinamiento del 153 $\%$ en estos lugares (El Tiempo, 2020b). Es decir, el hacinamiento carcelario y sus efectos en contra de la población privada de la libertad, se disminuyó en los establecimientos penitenciarios y carcelarios, trasladando esta carga a los centros de reclusión transitorios. 
velocidad y explica que los reclusos se sientan más desprotegidos y vulnerables por este motivo y exijan una mayor protección.

Ahora bien, aunque las facultades del director general del INPEC -con base en la declaratoria de emergencia penitenciaria y carcelaria-, le permiten hacer uso racional de los medios extraordinarios de coerción y el reclamo del apoyo de la Fuerza Pública, en los hechos acaecidos el 21 de marzo de 2020 se hizo efectivo el apoyo de la Fuerza Pública sin la existencia de dicha declaratoria, lo que en todo caso encuentra sustento normativo en los artículos 31 y 32 del CPC. En consecuencia, se deberá analizar la racionalidad de los medios empleados contra la población privada de la libertad y la participación de la Fuerza Pública acorde con los parámetros de la legalidad y el respeto de los derechos humanos.

Dentro de las medidas adoptadas por el director del INPEC con base en la actual emergencia penitenciaria y carcelaria, encontramos, entre otras, las siguientes:

Tabla 2 . Medidas adoptadas con base en la Resolución 001144 de 2020

\begin{tabular}{|c|c|}
\hline Acto administrativo & Contenido \\
\hline Resolución 01274 (25-03-20) & $\begin{array}{l}\text { Urgencia manifiesta (traslados presupuestales y contratación directa } \\
\text { de bienes, servicios y obras para conjurar la emergencia). }\end{array}$ \\
\hline Circular 00005 (17-03-20) & $\begin{array}{l}\text { Medidas para la contención del COVID-19 en los servidores peniten- } \\
\text { ciarios y contratistas. }\end{array}$ \\
\hline Circular 00007 (20-03-20) & $\begin{array}{l}\text { Medidas preventivas de seguridad - Aislamiento de personal del Cuerpo } \\
\text { de Custodia y Vigilancia. }\end{array}$ \\
\hline Circular 00008 (26-03-20) & Uso de la fuerza. \\
\hline Circular 00009 (28-03-20) & Acciones de monitoreo en derechos humanos. \\
\hline Circular 00012 (01-04-20) & $\begin{array}{l}\text { Términos para respuesta al derecho de petición conforme el Decreto } \\
491 \text { de } 2020 \text {. }\end{array}$ \\
\hline Circular 00017 (08-04-20) & $\begin{array}{l}\text { Visitas virtuales familiares e instrucciones para la implementación de } \\
\text { estrategias que faciliten el contacto familiar de la población privada de } \\
\text { la libertad durante el estado de emergencia sanitaria. }\end{array}$ \\
\hline Circular 00018 (14-04-20) & $\begin{array}{l}\text { Continuación de medidas de aislamiento obligatorio a partir del } 13 \text { de } \\
\text { abril de } 2020 \text {. }\end{array}$ \\
\hline Circular 00019 (16-04-20) & $\begin{array}{l}\text { Aplicación de lineamientos para control, prevención y manejo de casos } \\
\text { por COVID-19 para la población privada de la libertad en Colombia. }\end{array}$ \\
\hline
\end{tabular}

Fuente: Elaboración propia.

Como se puede observar en la tabla $\mathrm{n} . \underline{\mathrm{o}}$ 2, las medidas adoptadas por el INPEC son de tipo operativo, siendo importante para los efectos de este trabajo 
la Circular 00008. Con relación a esta, en el siguiente apartado analizaremos el uso de la fuerza con anterioridad a la declaratoria de emergencia penitenciaria y carcelaria -a propósito de los hechos acaecidos el 21 de marzo de 2020-, así como la situación después de esta fecha.

\section{El uso de la fuerza en el marco del ECI carcelario}

En Colombia, la Corte Constitucional ha puesto de presente la especial condición de vulnerabilidad de las personas privadas de la libertad (relación especial de sujeción) ${ }^{23}$; sin embargo, el hecho de que la Fuerza Pública reaccione de forma represiva en caso de que existan protestas como las que tuvieron lugar, que tenían como fin exigir una estrategia de prevención por parte del Estado que protegiera a las personas privadas de la libertad del riesgo causado por el coronavirus, es bastante preocupante, pues se genera un escenario propicio para que tenga lugar la vulneración de los derechos de los reclusos, especialmente el derecho a la integridad personal e incluso el derecho a la vida ${ }^{24}$. En el ámbito internacional, encontramos que la Suprema Corte de los Estados Unidos (caso Hudson vs. McMillian), estableció que el uso de fuerza física excesiva contra un prisionero constituye un castigo cruel e inusual, incluso cuando el preso no presenta lesiones graves (Aramburu, 2013).

Recordemos que la privación de la libertad suspende el derecho de locomoción del sujeto, pero derechos como la vida y la integridad personal permanecen intocables (Hernández, 2019, p. 161). Por lo anterior, el riesgo causado como consecuencia de la pandemia debe ser mitigado por parte de las autoridades con

23 En la Sentencia T-596 de 1992 la Corte Constitucional se refirió a los internos como personas en especial situación de sujeción respecto de la administración. Posteriormente, dicha Corporación profundizó este concepto, afirmando que [...] la relación de sometimiento que mantienen con el Estado no les quita su calidad de sujetos activos de derechos y si bien, en razón de su comportamiento 'antisocial anterior' tienen algunas de sus garantías suspendidas, como la libertad, [...] gozan del ejercicio de presupuestos fundamentales básicos en forma plena, como la vida, la salud, la integridad física y la dignidad humana" (Sentencia T-143 de 2017).

24 La Corte Constitucional se ha referido en su jurisprudencia al uso de la fuerza por parte del Estado, haciendo hincapié en que este debe ser siempre regido por los parámetros de estricta excepcionalidad y proporcionalidad. Así, [...] la actividad armada del Estado será compatible con la Constitución, sólo cuando [...] (iii) se ejerza de manera imperiosa, esto es, cuando no exista ninguna otra medida disuasoria que permita el cumplimiento de las normas legales y, del mismo modo, se trate de un escenario donde resulte jurídicamente admisible el uso de la fuerza; y (iv) dicho uso cumpla con criterios de proporcionalidad, también en sentido estricto, lo que implica que solamente pueda llevarse a cabo en la medida absolutamente necesaria para confrontar la amenaza a bienes constitucionales de la más alta entidad" (Sentencia C-082 de 2018). En el mismo sentido, la sentencia de tutela del 22 de septiembre de 2020 (STC7641-2020, Radicación n.ำ 11001-22-03-000-2019-02527-02, M.P. Luis Armando Tolosa Villabona) señala: “El uso de la fuerza por parte de los cuerpos de seguridad estatales debe estar definido por la excepcionalidad, y debe ser planeado y limitado proporcionalmente por las autoridades. Así las cosas, es imprescindible que los miembros de la fuerza pública conozcan las disposiciones normativas que permiten el uso de las armas letales y no letales, y que tengan el entrenamiento adecuado para que en el evento en que deban decidir acerca de su uso posean los elementos de juicio para hacerlo". 
miras a evitar una masacre de la población privada de la libertad. Así, resulta entendible la reacción de los reclusos por el temor que genera una situación de potencial riesgo sobre sus vidas. Insistimos que el hacinamiento de los establecimientos de reclusión nacionales propicia la violencia (Sentencia T-153 de 1998) y en la coyuntura actual, incrementa la gravedad de la pandemia.

En virtud del estado de emergencia penitenciaria y carcelaria, el 26 de marzo de 2020, mediante Circular 000008 (INPEC) se recordaron las instrucciones adoptadas sobre el uso de la fuerza [Resolución 00192 de 2018 (INPEC)], en concordancia con el artículo 49 del CPC, las cuales consisten en (i) el uso de la fuerza como último recurso y en caso de que sea estrictamente necesario; (ii) el nivel de intervención debe ser proporcional al nivel de resistencia; (iii) utilización de elementos autorizados que cumplan con las especificaciones técnicas dadas por el INPEC; (iv) el uso excepcional y diferenciado de las armas de fuego solo opera en defensa propia o de otras personas ${ }^{25}$, incluyendo el peligro de fuga; (v) el uso de la fuerza debe quedar documentado; (vi) responsabilidad de instrucción, ejecución y denuncia respecto al uso indebido de la fuerza, por parte del cuadro de mando y (vii) investigaciones penales y disciplinarias frente al uso indebido de la fuerza.

En lo que atañe al peligro de fuga y las instrucciones adoptadas mediante el acto administrativo del 2018 por parte del INPEC, consideramos necesario analizar el contexto en el que se da el intento de escape, ya que, si con esta actuación no se verifica una amenaza real o inminente para otra vida, resulta injustificado el uso de la fuerza potencialmente letal (Silva y Padilla, 2019, p. 66). De esta manera, la justificación del Ministerio de Justicia sobre el "plan criminal de fugas" que ameritó el uso de armas de fuego (BBC, 2020), no puede ser aceptada automáticamente, por lo que merece un análisis detallado para determinar si el pretendido peligro de fuga amenazó la vida de los guardias, de otros reclusos o de terceros.

Además, se debe tener en cuenta que, en el marco de los niveles del modelo de uso de la fuerza, se debe analizar la percepción de la conducta de la persona con la que se interactúa, valorando el riesgo y la amenaza (INPEC, 2019) ${ }^{26}$. En todos los niveles se deben utilizar técnicas verbales, a las que se van acumulando técnicas de control y de defensa, como se observa en la Tabla n. $\stackrel{-}{3}$ :

25 Contra un peligro inminente de muerte o lesiones graves, o con el propósito de evitar la comisión de un delito particularmente grave que entrañe una seria amenaza para la vida e integridad personal.

26 Insistimos, el uso de la fuerza en los establecimientos de reclusión se debe activar [...] sólo en circunstancias extremas, cuando hayan fracasado todas las demás intervenciones, individuales o colectivas, podrá estar justificado el uso de la fuerza como método legítimo para restaurar el orden. Debe ser absolutamente el último recurso. Dado que las prisiones son comunidades cerradas en las que puede producirse fácilmente un abuso de autoridad en tales circunstancias, debe existir una serie de procedimientos específicos y transparentes para el uso de la fuerza" (Coyle, 2002, p. 60). 
Tabla 3 . Niveles del modelo de uso de la fuerza

\begin{tabular}{|c|c|c|}
\hline Nivel & $\begin{array}{l}\text { Percepción de la } \\
\text { conducta }\end{array}$ & Respuesta razonable \\
\hline Primer nivel & $\begin{array}{l}\text { Acatamiento de las } \\
\text { órdenes }\end{array}$ & Técnicas verbales de negociación y persuasión. \\
\hline Segundo nivel & Resistencia pasiva & $\begin{array}{l}\text { Desplazamiento de la persona privada de la libertad hacia } \\
\text { un lugar seguro, para lo cual se pueden emplear herra- } \\
\text { mientas de control físico como el bastón de mando, de } \\
\text { manera preventiva. }\end{array}$ \\
\hline Tercer nivel & $\begin{array}{l}\text { Resistencia física } \\
\text { activa }\end{array}$ & $\begin{array}{l}\text { Técnicas de control físico como la inmovilización. Uso de } \\
\text { medios coercitivos y elementos de protección. }\end{array}$ \\
\hline Cuarto nivel & Agresión no letal & $\begin{array}{c}\text { Técnicas de defensa y utilización de tonfa, restricciones, } \\
\text { agente químico y/o aspersor de gas y equipo control } \\
\text { antidisturbios. }\end{array}$ \\
\hline Quinto nivel & $\begin{array}{l}\text { Agresión potencial- } \\
\text { mente letal }\end{array}$ & $\begin{array}{l}\text { Técnicas de defensa potencialmente letal (uso de armas } \\
\text { de fuego). }\end{array}$ \\
\hline
\end{tabular}

Fuente: Elaboración propia con base en INPEC (2019).

Frente a los hechos ocurridos el 21 de marzo de 2020 en la CPMS La Modelo, algunas organizaciones han denunciado que tanto el INPEC como la Policía Nacional hicieron uso excesivo de la fuerza (Asociación Minga, 2020). Además, la Procuraduría General de la Nación abrió indagación preliminar para establecer responsabilidades en los hechos que llevaron a la retoma del establecimiento de reclusión (Pulzo, 2020) y, del mismo modo, la Fiscalía General de la Nación asignó un fiscal de Derechos Humanos para que se determinen las responsabilidades a que haya lugar en torno a esos hechos (Fiscalía General de la Nación, 2020) ${ }^{27}$.

27 Aunque inicialmente la Fiscalía había señalado que el motín había sido orquestado por un disidente de las FARC-EP y un integrante del ELN, es importante tener en cuenta que en el CPMS La Modelo solo hay dos sindicados por hacer parte del ELN y los integrantes de las FARC están en el proceso ante la Jurisdicción Especial para la Paz (JEP), a lo que se suma que la mayoría de los heridos corresponden a los patios en los que está alojada la población privada de la libertad por delitos comunes (Cerosetenta, 2020a). En la primera parte de la infografía de Cerosetenta (2020b) se observa que los desórdenes se localizan en el ala sur, especialmente en los patios 4 y 5 , donde el perfil de los internos efectivamente es de sindicados y condenados por delitos comunes (Hernández, 2018, p. 174), en todo caso en el segmento 7 se observa quema de colchones en el ala norte (patio $1 \mathrm{~A}$ - sindicados y condenados por delitos sexuales) y en los segmentos 14 y 15 se ve un cuerpo (herido o muerto) en el patio 1B (sindicados o condenados por delitos relacionados con actividades paramilitares). Por lo anterior, la hipótesis inicial de la Fiscalía General de la Nación resulta por lo menos sospechosa. 
La violencia estatal y el abuso de la fuerza por parte de los guardias penitenciarios hacen parte de la experiencia carcelaria latinoamericana ${ }^{28}$. En Colombia, entre 2007 y 2008, el INPEC registró 79 faltas disciplinarias de maltrato físico y verbal en contra de los internos (Coalición Colombiana contra la Tortura, 2009, p. 32 ), siendo estas, violaciones directas de sus derechos humanos. Adicionalmente se registraron 15 víctimas de ejecuciones extrajudiciales en el periodo 2002-2010, siendo el INPEC el probable responsable (Monitor Fuerza Letal, 2019, p. 50).

En este contexto, autores como Bello y Parra (2016), plantean que la relación entre guardias y reclusos dentro de las cárceles colombianas se encuentra instaurada sobre el concepto del necro-poder. Este concepto implica que " $[; \ldots]$ existen campos en los cuales los sujetos son despojados de la autonomía sobre sus propios cuerpos y de su reconocimiento como ciudadanos" (p. 371) y, como consecuencia, se reduce a los sujetos a la "nuda vida", "[;...] es decir, una vida reducida a una existencia biológica despojada de su estatus político e inmersa en un Estado de excepción, donde el derecho se encuentra suspendido de manera permanente" (de Dardel, 2015, p. 54).

En el mismo sentido Umaña y Cordero (2019, p. 335) analizan las muertes de las personas privadas de la libertad entre los años 2012 y 2018, documentando 363 muertes violentas en espacios de vigilancia directa, según los datos del Instituto Nacional de Medicina Legal y Ciencias Forenses (INMLCF), lo que resulta contrario a la imagen civilizatoria del sistema penal. Al respecto es importante reiterar la crítica sobre la insuficiencia de tener escrito en papel la protección a los derechos humanos de las personas privadas de la libertad, cuando los actos de las autoridades van a ser contrarios a estos postulados (Martin, 2006. p. 150).

Insistimos, las protestas del 21 de marzo de 2020 fueron tildadas como un intento de fuga, una afrenta evidente contra la autoridad, lo que aparentemente legitimó a los guardias a usar la violencia en contra de los reclusos. No obstante, no hay evidencia de que los internos hayan atacado con armas de fuego a la guardia, lo que denota una clara desproporción frente al uso racional de la fuerza, aunque sí se evidencia que tuvieron acceso a un fusil (Cerosetenta, 2020b) ${ }^{29}$ y se observa un impacto (aparentemente de un proyectil) en la garita 8, donde se encontraba un guardián, quien tuvo que abandonar este lugar por el fuego que prendieron algunos reclusos en la base de esta estructura (Revista Semana, 2020b).

"La fuerza estatal ejercida de forma violenta por los guardias; la creación de escuadrones que ingresan a las cárceles en los casos de motines para restaurar el orden penitenciario a través de la muerte; los internos organizados que ejercen su poder a través del miedo, el castigo y la muerte; la permanente amenaza de violencia física ligada a una convivencia en situaciones extremas derivada de la lucha violenta por el control de la cárcel, y la dificultad de acceder a bienes básicos para el sustento cotidiano, entre otras realidades violentas, hacen del castigo corporal una parte central de la experiencia carcelaria latinoamericana" (Ariza y Tamayo, 2020, p. 89).

En el segmento 18 de la infografía se observa que los internos utilizaron este fusil para hacer tiros al aire. 
En este caso particular, en el que corría peligro la vida de un guardia, se justificaría el uso de armas de fuego en contra de sus agresores. Sin embargo, los hallazgos documentados hasta el momento no muestran que las lesiones y muertes de la población privada de la libertad hayan ocurrido como consecuencia de proteger la vida e integridad personal de este guardia. Tampoco que las 24 personas fallecidas sean las mismas que hayan prendido fuego a la garita 8 o impactado la misma con un proyectil de arma de fuego.

La deshumanización de las personas privadas de la libertad, derivada de la normalización de la violencia como acto estatal que tiene como consecuencia el abuso constante de la autoridad, se materializa en la utilización de dicha violencia para someter al otro. Así, entre 2010 y 2014, el INMLCF valoró a 2.425 personas privadas de la libertad que presentaban lesiones personales y, por otro lado, la Fiscalía General de la Nación informó que al momento se encontraban en curso 226 procesos contra miembros del INPEC por el delito de lesiones personales (Grupo de Prisiones, 2019, p. 32). Dentro de esta dinámica estatal, no sorprende el saldo de 24 muertes como consecuencia de las protestas que tuvieron lugar en la CPMS La Modelo.

Frente a estos hechos, y a la luz del sistema interamericano de derechos humanos, consideramos que la responsabilidad del Estado podría encontrarse comprometida $^{30}$. Así, en el informe n. ${ }^{\circ} 34$ (13 de abril de 2000), en relación con el caso 11291 Carandirú - Brasil, que fue objeto de solución amistosa ${ }^{31}$ se señaló que el Estado tiene el derecho y la obligación de solucionar un motín, limitando en todo caso el uso de la fuerza ${ }^{32}$. El esclarecimiento de los hechos ocurridos el 21 de marzo de 2020, con su lamentable desenlace en la CPMS La Modelo, deberá demostrar la legítima defensa y la proporcionalidad respecto de los medios empleados por las personas privadas de la libertad, así como la necesidad de responder con la fuerza letal.

30 Como lo explica Juan Manuel Carreño (2016): [...] daño causado en esos casos en que el Estado incurre en responsabilidad por violaciones de los derechos humanos es particularmente grave puesto que quienes son explícitamente encargados de la protección de la ciudadanía han, por el contrario, abusado de su poder en perjuicio de la población" (p. 19).

31 Sobre las soluciones amistosas en el sistema interamericano de derechos humanos como forma de justicia restaurativa se puede consultar Méndez y Hernández (2020).

32 No obstante, en este caso “63. La acción de la Policía, tal como está descrita en la petición y confirmada por las investigaciones oficiales y la opinión de expertos, se llevó a cabo con absoluto desprecio por la vida de los reclusos, y demostrando una actitud retaliatoria y punitiva, absolutamente contraria a las garantías que debe ofrecer la acción policial. La Comisión anota que las muertes no correspondieron a situaciones de legítima defensa ni de desarme de los recluidos, ya que las armas que éstos tenían, de factura casera, habían sido arrojadas al patio al entrar los policías. No se comprobó la existencia de ningún arma de fuego en poder de los revoltosos, ni que hayan efectuado disparo alguno de arma de fuego contra la policía. Su actitud violenta inicial fue rápidamente superada por la entrada masiva de la policía fuertemente pertrechada". 
Empero, el miedo y las protestas que realizaron los reclusos ese día, parecen estar justificados por la posibilidad de contagio del COVID-19 en medio de un ambiente hacinado. Las cifras ascendentes de contagiados lo confirman ${ }^{33}$. Por su parte, la respuesta del Estado se muestra como desproporcionada. Según versiones de los internos, la manifestación inició como un "cacerolazo" golpeando platos contra las rejas de las celdas y terminó con disparos por parte del INPEC y la Policía Nacional (Cerosetenta, 2020a).

Tras comparar los resultados: 24 reclusos muertos y 83 heridos, frente a 11 funcionarios del INPEC heridos y ningún muerto, se observa una desproporción. No se puede justificar la afectación a la salud y la vida del personal de seguridad, pero las cifras demuestran que la autoridad usó más fuerza de la que era necesaria. Cabe resaltar que de las 24 personas privadas de la libertad que murieron por esos hechos, 22 de ellas murieron por impactos de bala. Es evidente el exceso de uso de la fuerza al presentarse este escenario. Otros reclusos recibieron disparos por la espalda, encontrándose en estado de indefensión, lo que demuestra que los guardias utilizaron la fuerza letal de manera desmedida (Revista Semana, 2020a).

Se debe mencionar adicionalmente que, según investigadores forenses, la mayoría de los disparos estaban dirigidos a acabar con la vida de los internos, ya que se encontraron impactos de bala en la cabeza, cara, cuello y tórax de algunos de los reclusos. Uno de los internos fue hallado con 5 disparos en su cuerpo. Esto, teniendo en cuenta las circunstancias "puede ser catalogado como sevicia" (El Colombiano, 2020).

En los videos que la Revista Semana reveló en el mes de junio de 2020 se encuentran imágenes en las cuales hay internos desnudos en una vía destapada mientras que funcionarios del INPEC detrás de ellos los obligan a gatear por la carretera. Otros videos muestran guardias amenazando y golpeando a internos también desnudos acostados en el piso. "No menos grave es lo que ocurrió con decenas de detenidos, que tras rendirse sufrieron torturas y golpizas" (Revista Semana, 2020a) $)^{34}$.

En la respuesta del Ministerio de Justicia (2020a) al auto de la Corte Constitucional datado 3 de junio de 2020, se afirma que el uso de la fuerza siempre ha estado ajustado a los "Principios básicos sobre el empleo de la fuerza y de armas de fuego por los funcionarios encargados de hacer cumplir la ley de la Organización

33 Cfr. https://especiales.elespectador.com/covid-19-en-las-carceles/tablero-de-datos/

34 La Revista Semana (2020a) reveló los videos que grabaron las cámaras de seguridad de la Cárcel La Modelo y califica los acontecimientos del 21 de marzo de 2020 como una "masacre". Se suma así esta fecha, a la historia de las masacres en la experiencia carcelaria colombiana, rememorando el año 2000 y el infierno en la modelo (Ariza \& Iturralde, 2019, p. 89). 
de Naciones Unidas" (p. 94) ${ }^{35}$. En todo caso, después de las desgarradoras imágenes del 21 de marzo de 2020 que han salido a la luz pública, el uso excesivo de la fuerza por parte de agentes estatales sobre personas en estado de vulnerabilidad dentro de los centros penitenciarios se ha hecho más visible, generando una mayor preocupación y exigencia de respuestas por parte de la sociedad.

El abuso de poder ha sido tan evidente alrededor del mundo, que el 17 de abril del 2020, la Oficina del Alto Comisionado de Derechos Humanos de las Naciones Unidas publicó un comunicado expresando su preocupación por el incremento de los abusos de la fuerza contra personas en situaciones vulnerables, entre ellas los privados de la libertad. La entidad expresa que las medidas de seguridad tomadas para mitigar la crisis del COVID-19 no pueden ser excusa para estos excesos (ONU, 2020), e incentiva a la protección de la dignidad humana incluso bajo un estado de excepción, haciendo un llamado a investigar las violaciones a los derechos humanos.

\section{Conclusiones}

Hasta el momento, la declaratoria de emergencia penitenciaria y carcelaria no ha brindado soluciones de fondo para mitigar el riesgo de contagio y las personas privadas de la libertad no han podido llevar a cabo la estrategia de distanciamiento social, dentro de un sistema que alberga aproximadamente un $24 \%$ más de las personas para las que tiene capacidad en los establecimientos penitenciarios y carcelarios a cargo del INPEC y más de un $120 \%$ de las personas para las que tiene capacidad los centros de reclusión transitorios.

El coronavirus ya ha cobrado 5 vidas: las vidas de 5 personas que se encontraban bajo la protección y vigilancia del Estado, pero para las cuales no se plantearon soluciones reales ni oportunas. A estas 5 vidas debemos sumar otras 24 que fallecieron en los motines del 21 de marzo de 2020 en la CPMS La Modelo. Hechos lamentables que acaecieron no solo por la omisión de protección del Estado, sino por el probable actuar abusivo de sus agentes.

Aunque la declaratoria de emergencia penitenciaria y carcelaria es insuficiente, su efecto simbólico nos motiva como comunidad a volver la mirada hacia la situación carcelaria del país. En adición a lo anterior, el cubrimiento por parte de los medios de comunicación de los hechos ocurridos el 21 de marzo de 2020 y, en general, de la situación carcelaria en tiempos del COVID-19, también tiene

35 "Ahí se establece el criterio del uso diferenciado y progresivo de la fuerza, priorizando los medios no violentos y se prohíbe el uso de armas letales, salvo cuando sea en defensa propia o de otras personas" (Saldaña y Portocarrero, 2017, p. 319). 
un efecto simbólico: exponer, presionar, controlar y exigir a las autoridades que adecúen su comportamiento en procura de salvaguardar los derechos de las personas privadas de la libertad, ya que la comunidad en general reprocha los abusos cometidos, así como la precariedad de las condiciones en que se encuentran los centros de reclusión.

Insistimos, dentro de un Estado Social y Democrático de Derecho, cuyos cimientos son el respeto a la vida y a la dignidad humana, las autoridades deben velar por su protección y deben sujetarse a la ley al igual que el resto de los ciudadanos. Por lo anterior, resulta inaceptable que en la actualidad se sigan presentando este tipo de excesos por parte de la autoridad, más si tenemos en cuenta la situación crítica que viven día a día las personas privadas de la libertad y la desigualdad de condiciones en que se encuentran al enfrentarse con un agente de la Fuerza Pública.

Es importante hacer un llamado a las autoridades de control para que esclarezcan lo ocurrido y sancionen los actos abusivos. El uso racional de la fuerza contribuiría a fortalecer la confianza y el respeto por las instituciones, y permitiría legitimar el poder estatal como medio para mantener la seguridad y el orden. Por lo pronto, el rótulo racional se observa como una expectativa que le otorga un elegante y apócrifo calificativo al uso de la fuerza en el contexto nacional, con base en la situación documentada este trabajo.

Así las cosas, desde el Semillero en Derecho Penitenciario de la Pontificia Universidad Javeriana seguiremos actuando como observadores de lo que pasa al interior de los muros carcelarios, para poner en evidencia y denunciar todas aquellas situaciones en las que se vulneren los derechos de la población privada de la libertad.

\section{Referencias bibliográficas}

Acevedo, A. y Villabona, J. (2020). La prensa como fuente documental para el análisis y la investigación social. Historia y memoria, (20), 347-373.

Aramburu, T. J. (1999). The Role of "De Minimis" Injury in the Excessive Force Determination: Taylor v. McDuffie and the Fourth Circuit Stand Alone. BYU J. Pub. L., 14, 313-328.

Ariza, L.J. \& Iturralde, M.A. (2019). The Bullet in the Glass: War, Death, and the Meaning of Penitentiary Experience in Colombia. International Criminal Justice Review, 30(1), 83-98.

Ariza, L.J. y Tamayo, F.L. (2020). El cuerpo de los condenados. Cárcel y violencia en América Latina. Revista de Estudios Sociales, (73), 83-95.

Asociación Minga. (22 de marzo de 2020). INPEC y POLICÍA hacen uso excesivo de la fuerza contra la población privada de la libertad. Recuperado de https:// 
asociacionminga.co/index.php/2020/03/22/inpec-y-policia-hacen-uso-excesivo-de-la-fuerza-contra-la-poblacion-privada-de-la-libertad/, https://www. justiciaypazcolombia.com/inpec-y-policia-hacen-uso-excesivo-de-la-fuerzacontra-la-poblacion-privada-de-la-libertad/

Augé, M. (2005). Los No Lugares. Espacios del Anonimato. Barcelona: Gedisa

BBC. (22 de marzo de 2020). Cárcel La Modelo: un motín en una prisión de Colombia deja 23 muertos en medio de la tensión por el coronavirus. $B B C$. Recuperado de https://www.bbc.com/mundo/noticias-america-latina-51998800

Bello, J.A. y Parra, G. (2016). Cárceles de la muerte: necropolítica y sistema carcelario en Colombia. Universitas Humanística, (82), 365-395.

Carreño, J.M. (2016). Las cárceles como espacios de violación a los Derechos Humanos, estudio de caso: cárcel La Modelo de Bogotá (2002-2010) (tesis de pregrado). Universidad del Rosario, Bogotá, Colombia Recuperado de https://repository.urosario.edu.co/ bitstream/handle/10336/12488/1026266103-2016.pdf?sequence=1

Centro de Estudios de Droga y Derecho (CEDD) y Centro de Estudios de Derecho, Justicia y Sociedad (Dejusticia). (2020). Aliviar el hacinamiento carcelario: salvavidas en tiempos de COVID. Recuperado de https://www.dejusticia.org/aliviar-elhacinamiento-carcelario-salvavidas-en-tiempos-de-covid-19/

Centros para el Control y la Prevención de Enfermedades (CDC). (16 de junio de 2020). Cómo se propaga el COVID-19. Recuperado de https://espanol.cdc.gov/ coronavirus/2019-ncov/prevent-getting-sick/how-covid-spreads.html

Cerosetenta. (2 de diciembre de 2019). Son 34. Cerosetenta. Recuperado de https:// cerosetenta.uniandes.edu.co/son-34-muertes-esmad/

Cerosetenta. (17 de mayo de 2020a). El silencio del INPEC sobre el motín de la Modelo. Cerosetenta. Recuperado de https://cerosetenta.uniandes.edu.co/el-silencio-delinpec-sobre-el-motin-de-la-modelo/

Cerosetenta. (2020b). Siete horas de angustia en la modelo. Cerosetenta. Recuperado de https://cerosetenta.uniandes.edu.co/siete-horas-de-angustia-en-la-modelo/

Coalición Colombiana contra la Tortura. (2009). Informe alternativo sobre tortura, tratos crueles, inhumanos o degradantes Colombia 2003-2009.

Colombia. Congreso de Colombia. (20 de enero de 2014). Ley 1709. Por la cual se reforman algunos artículos de la Ley 65 de 1993, de la Ley 599 de 2000, de la Ley 55 de 1985 y se dictan otras disposiciones. Diario Oficial n.o 49.039 .

Colombia. Corte Constitucional. (10 de diciembre de 1992). Sentencia T-596/92. [MP Ciro Angarita Barón).

Colombia. Corte Constitucional. (19 de julio de 1995). Sentencia C-318/95. [MP Alejandro Martínez Caballero] .

Colombia. Corte Constitucional. (27de octubre de 1998). Sentencia T-606/98. [MP José Gregorio Hernández Galindo] . 
Colombia. Corte Constitucional. (28 de abril de 1998). Sentencia T-153/98. [MP Eduardo Cifuentes Muñoz] .

Colombia. Corte Constitucional. (28 de junio de 2013). Sentencia T-388/13. [MP María Victoria Calle Correa].

Colombia. Corte Constitucional. (16 de diciembre de 2015). Sentencia T-762. [MS Gloria Stella Ortiz Delgado].

Colombia. Corte Constitucional. (20 de mayo de 2020). Sentencia C-145/20. [MP José Fernando Reyes Cuartas]

Colombia. Corte Constitucional. (12 de agosto de 2020). Sentencia C-307/20). [MP Luis Guillermo Guerrero Pérez].

Comisión Interamericana de Derechos Humanos. (13 de abril de 2000). Informe n. 34 en relación con el caso 11.291 Carandirú - Brasil. Recuperado de http://www. cidh.oas.org/annualrep/99span/De\%20fondo/Brasil11291.htm

Coyle, A. (2002). La administración penitenciaria en el contexto de los derechos humanos. Manual para el personal penitenciario) Londres: Centro Internacional de Estudios Penitenciarios.

Dardel, J. (2015). Resistiendo la "nuda vida": los prisioneros como agentes en la era de la nueva cultura penitenciaria en Colombia. Revista Crítica Penal y Poder, 8, 47-65.

Defensoría del Pueblo - Defensoría Delegada para la Política Criminal y Penitenciaria. (2005). Informe sobre prestación de servicios de salud en centros penitenciarios y carcelarios de Colombia. Recuperado de https://www.defensoria.gov.co/es/ public/Informesdefensoriales/797/Informe-sobre-prestaci\%C3\%B3n-deservicios-de-salud-en-centros-penitenciarios-y-carcelarios-de-Colombia-Informes-defensoriales---C\%C3\%A1rceles-Informes-defensoriales---Salud.htm

DW. (2020). Motines exponen vulnerabilidad de presos en Colombia ante llegada del coronavirus. DW. Recuperado de https://www.dw.com/es/motines-exponen-vulnerabilidad-de-presos-en-colombia-ante-llegada-del-coronavirus/a-52904366

El Colombiano. (7 de junio de 2020). INPEC se pronuncia sobre presunto exceso de fuerza en control de motín de cárcel La Modelo. El Colombiano. Recuperado de https://www.elcolombiano.com/colombia/operativo-de-las-autoridades-enmotin-de-carcel-modelo-de-bogota-DA13131367

El Heraldo. (22 de marzo de 2020). Reclusos protagonizan motines en cárceles del país. El Heraldo. Recuperado de https: //www.elheraldo.co/colombia/en-videoreclusos-protagonizan-motines-en-carceles-del-pais-711196

El Tiempo. (11 de marzo de 2020a). Atención: la OMS declara pandemia por el nuevo coronavirus. El Tiempo. Recuperado de https://www.eltiempo.com/salud/ coronavirus-ya-es-una-pandemia-declara-la-oms-471524

El Tiempo. (11 de julio de 2020b). Más de 1.300 detenidos llevan un año en estaciones de policía. El Tiempo. Recuperado de https://www.eltiempo.com/justicia/ 
delitos/hacinamiento-en-estaciones-de-policia-y-uri-llega-al-153-por-ciento-516964

El Tiempo. (21 de marzo de 2020c). Sube a 196 el número de casos confirmados de coronavirus en Colombia. El Tiempo. Recuperado de https://www.eltiempo.com/ salud/coronavirus-casos-confirmados-de-covid-19-en-colombia-hoy-21-demarzo- 475548

El Tiempo. (5 de enero de 2018). Contraloría raja a la USPEC por mal servicio de salud de presos. El Tiempo. Recuperado de https://www.eltiempo.com/justicia/investigacion/contraloria-raja-a-la-uspec-por-mal-servicio-de-salud-de-presos-168434

Elsner, A. (2004). Gates of Injustice: The Crisis in America's Prisons. Upper Saddle River. NJ: Prentice Hall.

Escobar, J. G. (2018). ¿Quién mató a la tutela en materia de privación de libertad en Colombia?, Nuevo Foro Penal, 14(91), 43-79.

Fazio, H. (1998). La historia del tiempo presente: una historia en construcción. Historia crítica, (17), 47-57.

Fiscalía General de la Nación. (24 de marzo de 2020). Fiscalía evalúa varias hipótesis para determinar los responsables penales por los disturbios ocurridos en la cárcel La Modelo de Bogotá. Recuperado de https://www.fiscalia.gov.co/colombia/ fiscal-general-de-la-nacion/fiscalia-evalua-varias-hipotesis-para-determinarlos-responsables-penales-por-los-disturbios-ocurridos-en-la-carcel-la-modelode-bogota/

Garland, D. (1999). Castigo y sociedad moderna. Un estudio de teoría social (Trad. B. Ruiz). México D.F.: Siglo XXI Editores.

Grujić, Z. \& Milić, I. (2016). Prison Overcrowding-Mitigating the Consequences. In D. Kolarić \& D. Arčibalda (eds.), "Archibald Reiss Days" Thematic Conference Proceedings of International Significance (vol. 1) (pp. 286-295).

Gutiérrez, M. (2018). Dignidad en un no-lugar. En M. Gutiérrez y A. M. Olarte (eds.), Política criminal y abolicionismo, hacia una cultura restaurativa (pp. 231-266). Bogotá: Universidad Externado de Colombia.

Griffin, M. L. (1999). The influence of organizational climate on detention officers' readiness to use force in a county jail. Criminal Justice Review, 24(1), 1-26.

Grupo de Prisiones - Universidad de los Andes. (2019). Informe de Derechos Humanos del Sistema Penitenciario en Colombia (2017-2018). Recuperado de https://grupodeprisiones.uniandes.edu.co/images/2019/GrupoPrisiones.InformeDDHH2018.pdf

Hernández, P. (2017). Consideración teórica sobre la prensa como fuente historiográfica. Historia y comunicación social, 22(2), 465-477.

Hernández, N. (2018). El derecho penal de la cárcel. Una mirada al contexto colombiano con base en el giro punitivo y la tendencia al mayor encarcelamiento. Bogotá: Siglo del Hombre Editores, Universidad de los Andes, Universidad EAFIT. 
Hernández, N. (2019). Incompatibilidad de la detención preventiva con la presunción de inocencia. En M. Gutiérrez y A.M. Olarte (eds.), Los riesgos del punitivismo, presunción de inocencia e indignidad carcelaria en Colombia (pp. 155-184). Bogotá: Universidad Externado de Colombia.

Hernández, N. (2020). Comentario al auto del 29 de abril de 2020 (Radicado 56777) de la Corte Suprema de Justicia. Competencia para decidir sobre la detención y prisión domiciliarias transitorias en tiempos del COVID-19. Revista Nuevo Foro Penal, 16(94), 177-182.

Instituto Nacional Penitenciario y Carcelario (INPEC). (Sin fecha). Resoluciones 1505 (31-05-13), 2390 (10-05-16), 6401 (21-12-16), 192 (25-01-18), 00144 (22-0320), 01274 (25-03-20).

Instituto Nacional Penitenciario y Carcelario (INPEC). (2019). Info Humanos n.o 16. Los niveles del uso de la fuerza. Recuperado de https://inpec.gov.co/documents/20143/668169/INFO+HUMANOS+no.+16+NIVELES+DE+USO+DE+LA +FUERZA+VF.pdf/3dd1b4e5-6b7b-aa3f-dd0b-2cb62c9e3b3a?version=1.0

Instituto Nacional Penitenciario y Carcelario (INPEC). (2020). Circulares n. 000005 (17-03-20), 000007 (20-03-20), 000008 (26-03-20), 000009 (28-03-20), 000012 (01-04-20), 000017 (08-04-20), 000018 (14-04-20) у 000019 (16-04-20).

Instituto Nacional Penitenciario y Carcelario (INPEC). (2020). Tableros estadísticos. Recuperado de http://200.91.226.18:8080/jasperserver-pro/flow.html?_flow Id=dashboardRuntimeFlow\&dashboardResource=/public/DEV/dashboards / Dash_Poblacion_Intramural\&j_username=inpec_user\&j_password=inpec

Iturralde, M.A. (2011). Prisiones y castigo en Colombia: La construcción de un orden social excluyente. En L. J. Ariza y M. A. Iturralde (eds.), Los muros de la infamia. Prisiones en Colombia y en América Latina Bogotá: Universidad de los Andes.

Larrauri, E. (2015). Introducción a la criminología y al sistema penal. Madrid: Trotta.

Limoncelli, K. E., Mellow, J. \& Na, C. (2020). Determinants of Intercountry Prison Incarceration Rates and Overcrowding in Latin America and the Caribbean. International Criminal Justice Review, 30(1), 10-29.

López, J.D. (8 de julio de 2020). Hacinamiento carcelario está en su punto más bajo desde el 2011. El Tiempo. Recuperado de https://www.eltiempo.com/justicia/ servicios/se-reduce-hacinamiento-carcelario-por-el-coronavirus-al-punto-masbajo-en-10-anos-515974

Martin, S. J. (2006). Staff use of force in United States confinement settings. Wash. UJL \& Pol'y, 22, 145-154.

Matthews, R. (2003). Pagando tiempo. Una introducción a la sociología del encarcelamiento. Barcelona: Bellaterra.

Méndez, S.V. y Hernández, N. (2020). Justicia restaurativa y Sistema Interamericano de Derechos Humanos. ACDI Anuario Colombiano de Derecho Internacional, 13, 1-32. 
Ministerio de Justicia y del Derecho - Consejo Superior de Política Criminal. (2020a). Respuesta al Auto del 3 de junio 2020 de la Corte Constitucional sobre medidas de contingencia para enfrentar el COVID-19 en centros carcelarios. Recuperado de http://politicacriminal.gov.co/Noticias1/respuesta-auto-03-de-junio-2020

Ministerio de Justicia y del Derecho. (2020b). Respuesta a los Autos 19 de junio y 3 de julio de 2020 de la Corte Constitucional en el proceso de revisión de constitucionalidad del Decreto 804 de 2020. Recuperado de https://www.corteconstitucional. gov.co/secretaria/archivo.php?id=17357.

Ministerio de Justicia y del Derecho, Corporación Alemana para la Cooperación Internacional-GIZ-. (2017). Indicadores de Derechos Humanos en el Sistema Penitenciario y Carcelario. Primer informe.

Monitor Fuerza Letal. (2019). Monitor del Uso de la Fuerza Letal en América Latina: Un estudio comparativo de Brasil, Colombia, El Salvador, México y Venezuela. México: Centro de Investigación y Docencia Económicas.

Morales, F. (5 de mayo de 2020). Radiografía del acceso a la salud en las cárceles durante la pandemia. El Espectador. Recuperado de https://www.elespectador. com/coronavirus/radiografia-del-acceso-salud-en-las-carceles-durante-lapandemia-articulo-918081/

Naciones Unidas Derechos Humanos (ONU). Oficina del Alto Comisionado. (17 de abril de 2020). Las medidas de seguridad de COVID-19 no son una excusa para el uso excesivo de la fuerza, dicen los Relatores y las Relatoras Especiales de la ONU. Comunicado de prensa. Recuperado de https://www. hchr.org.co/index.php/informacion-publica/comunicados-de-prensa/ comunicados-del-alto-comisionado-en-el-mundo/9209-las-medidas-deseguridad-de-covid-19-no-son-una-excusa-para-el-uso-excesivo-de-la-fuerzadicen-los-relatores-y-las-relatoras-especiales-de-la-onu

Pulzo. (23 de marzo de 2020). Procurador habla de "retoma de La Modelo" e investigará uso excesivo de la fuerza. Pulzo. Recuperado de https://www.pulzo.com/nacion/ investigacion-funcionarios-carcel-modelo-por-motines-contra-coronavirusPP867093

Quintero, J., Navarro, A.M. y Meza, M.I. (2011). La figura del estado de cosas inconstitucionales como mecanismo de protección de los derechos fundamentales de la población vulnerable en Colombia. Revista Jurídica Mario Alario D’Filippo, 3, 69-80.

Revista Semana. (7 de junio de 2020a). 10 hora de terror. Revista Semana. Recuperado de https://www.semana.com/nacion/articulo/en-exclusiva-masacre-carcel-lamodelo-pruebas-del-amotinamiento-carcelario/677853

Revista Semana. (9 de junio de 2020b). Motín en La Modelo: el guardia al que iban a quemar vivo. Revista Semana. Recuperado de https://www.semana.com/ nacion/multimedia/asi-fue-el-enfrentamiento-entre-guardias-y-presos-enla-carcel-la-modelo/678438 
Saldaña, J. y Portocarrero, J. (2017). La violencia de las leyes: el uso de la fuerza y la criminalización de protestas socioambientales en el Perú. Derecho PUCP, (79), 311-352.

Sampedro, J.A. (1998). Apuntes sobre la resocialización en el sistema penitenciario colombiano. Eguzkilore, (12), 107-112.

Silva, C. y Padilla, S. (2019). Militarización y uso de la fuerza durante y después de la detención sobre la población privada de la libertad en México. Desacatos, (60), 58-77.

Sociedad de Criminología Latinoamericana (SOCLA) y Centro de Estudios Latinoamericanos sobre Inseguridad y Violencia (CELIV). (2020). Los efectos del coronavirus en las cárceles de Latinoamérica. Recuperado de https://criminologialatam. wordpress.com/2020/06/12/efectos-del-covid-19-carceles-de-latino-america/

Umaña, C.E. y Cordero, A.T. (2019). Análisis sobre muertes de personas privadas de la libertad: una realidad adversa para lograr un derecho penal garantista. En M. Gutiérrez y A. M. Olarte (eds.), Los riesgos del punitivismo, presunción de inocencia e indignidad carcelaria en Colombia (pp. 295-384). Bogotá: Universidad Externado de Colombia.

Uprimny, R. (12 de abril de 2020). Fiscalía, hacinamiento carcelario y COVID-19. Dejusticia. Recuperado de https://www.dejusticia.org/column/fiscalia-hacinamientocarcelario-y-covid-19/ 